\title{
Study on the Separation of Dienes by Means of Extractive Distillation with Propylene Carbonate*
}

\author{
by Minoru Enomoto** and Hides Inoue***
}

\begin{abstract}
Summary: ¿sing a binary mixture of isoprene and 2-methyl-2-butene as a feed charge, the effects on extractive distillation with propylene carbonate of various operating parameters such as feed and solvent temperatures, location of entry of the hydrocarbon feed and reflux ratio were studied.

Propylene carbonate was tested for its efficient use as an extractive distillation solvent for the separation of dienes from a $C_{5}$ fraction. As a result, a diene fraction containing no parafins and only a trace of olefins was obtained. The addition of ethyl carbitol to increase the miscibility of propylene carbonate with hydrocarbons could improve the recovery of the dienes.
\end{abstract}

\section{Introduction}

Recently, $\mathrm{C}_{5}$ dienes are industrially separated by extractive distillation using various solvents such as acetonitrile, $\mathrm{N}$-methyl-2-pyrrolidone, dimethyl formamide and they are used as monomers for various kinds of synthetic rubbers.

We carried out the study on the separation of isoprene from its mixture with 2-methyl-2-butene by means of extractive distillation using propylene carbonate and its mixture with another organic liquid as a selective solvent to study the effects of various operating parameters. Propylene carbonate (PC) has been found to be highly selective in the previous screening. ${ }^{1)}$ The solvent was also used for the separation of dienes from a $\mathrm{C}_{5}$ fraction. From the result of a series of continuous extractive distillation experiments, the high selectivity and applicability of PC for the separation of the dienes have been confirmed.

\section{Experimental}

\subsection{Apparatus}

The continuous extractive distillation unit used in this work is shown in Fig. 1. It is an Aldershow column made of glass tube which inner diameter, plate space and total plate number are $32 \mathrm{~mm}, 45$ $\mathrm{mm}$ and 50 , respectively. The perforated plate has holes of $0.8 \mathrm{~mm}$ diameter and the ratio of the perforated area to the tower cross section is $6 \%$. Muffle heaters are provided around the

* Received October 19, 1976

** National Research Institute for Pollution and Resources (1-1, Kawaguchi, 3-chome, Kawaguchi, Saitama. 332)

*** Shibaura Institute of Technology tower for the heat insulation by heating through the vacuum jacket from outside of the tower. For the final evaluation of a solvent for practical application, thermal efficiency of extractive distillation unit must be considered. However, since it is difficult to determine the heat balance in such a small Oldershow experimental distilla-

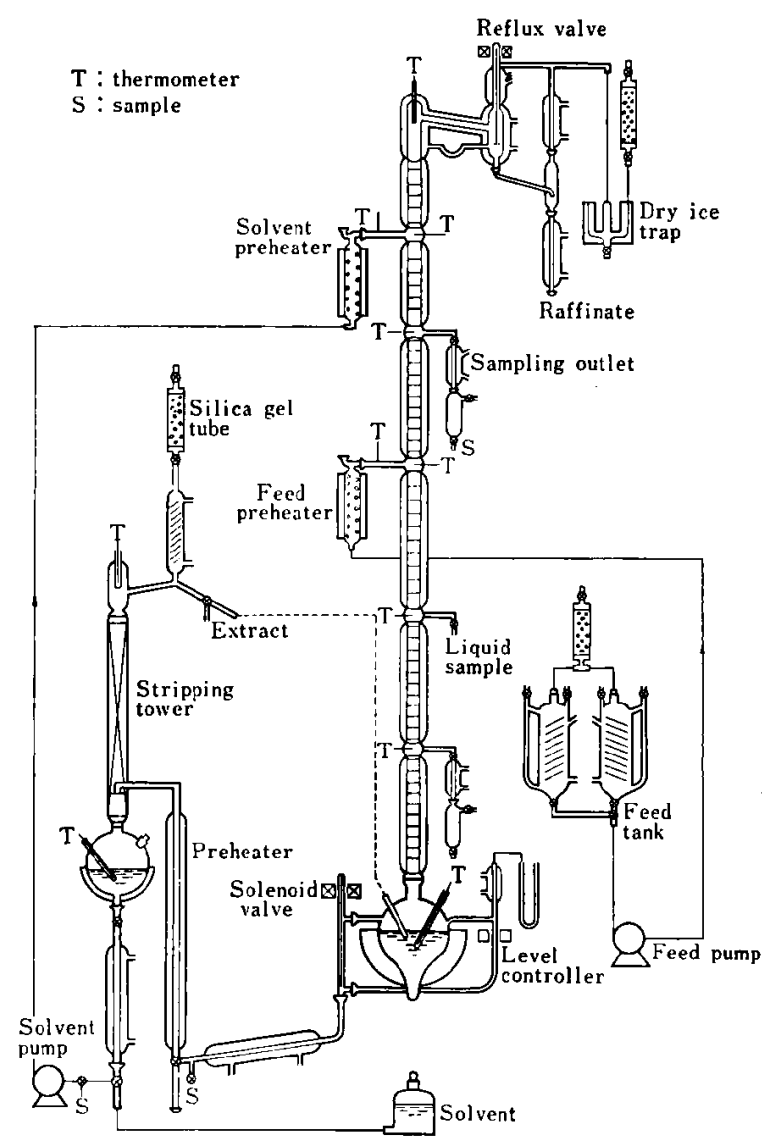

Fig. I Continuous Extractive Distillation Unit Used In the Work 
tion unit we carried out the experimets, maintaining nearly same heat input at various parts for cvcry runs and keeping the volume of the solvent flow rate constant at $50 \mathrm{cc} / \mathrm{min}$. Wattages of the still heater, the insulation heater No 1 (No. $1 \sim$ No. 10 plate from the bottom), No. 2 $(11 \sim 20)$, No. $3(21 \sim 30)$ and No. $4(31 \sim 40)$ were approximately $280 \mathrm{~W}, 260 \mathrm{~W}, 230 \mathrm{~W}, 180 \mathrm{~W}$ and $180 \mathrm{~W}$, respectively. The temperature at the outside surface of the vacuum jacket was maintained higher than the inside temperature by $20 \sim 30^{\circ} \mathrm{C}$.

The hydrocarbon stripping tower is $500 \mathrm{~mm}$ in height and $40 \mathrm{~mm}$ inner diameter. It is packed with Mcmahon packing. The temperature of the stripper was maintained constant. Cooling water for condensers comes from a brine refrigerator and temperature was maintained at about $0^{\circ} \mathrm{C}$.

The solvent free from diene hydrocarbons from the bottom of the stripper was sent to the 6th plate (counted from the top) of the extractive distillation tower through a solvent pump and a solvent preheater. While the hydrocarbon feed preheated in a preheater was sent to the middle of the tower through a feed pump and then a hydrocarbon preheater. The rich solvent accumulating in the still was withdrawn automatically through a solenoid valve and was sent to the middle of the stripper through the preheater.
It took about 5 hours for the whole system to attain to a steady state, judging from the temperatures and distillate compositions of both the extract (the distillate from the top of the stripper) and the raffinate (the distillate from the top of the extractive distillation tower). After attainning to a steady state, 2 or 3 sets of samples were taken out at several points shown in Fig. 1 after a certain elaspe of time and analysed according to the following procedure.

\subsection{Analytical Procedure}

There were about 30 components, which range from $\mathrm{C}_{4}$ to $\mathrm{C}_{6}$ hydrocarbons, in $a \mathrm{C}_{5}$ fraction. Since the boiling points of some components are very close each other, duplication of peaks occurred in analysing it by means of a gaschromatography with a capillary column (squalane). The same sample was analysed using more polar column (DMF) attached to another one. Then combining these data, the whole compositions were calculated. If a sample contained heavy components such as a solvent or dicyclopentadiene, another gaschromatography was used by being set so as to identify 2 peaks of hydrocarbon and a solvent. The entire calculation was performed by the off-line treatment of gaschromatographic data using a computer, as previously reported ${ }^{2}$.

Table 1 Compositions of Fractions in the Distillation of $\mathrm{C}_{5}$ Fraction

\begin{tabular}{|c|c|c|c|c|c|}
\hline Component & & Feed & Top & Bottom & Side Cut \\
\hline $\begin{array}{l}\mathrm{C}_{4} \text { fraction } \\
3 \text {-methyl-1-butene } \\
\text { 1,4 pentadiene } \\
\text { iso-pentane } \\
\text { 1-pentene } \\
\text { 2-methyl-1-butene } \\
\text { isoprene } \\
\text { n-pentane } \\
\text { trans-2-pentene } \\
\text { cis-2-pentene }\end{array}$ & $\begin{array}{l}\mathrm{C}_{4} \\
3 \mathrm{MBl} \\
1,4-\mathrm{PDe} \\
\text { iso-Pa } \\
1-\mathrm{Pe} \\
2 \mathrm{MBl} \\
\mathrm{IP} \\
n-\mathrm{Pa} \\
\text { trans-2-Pe } \\
\text { cis-2-Pe }\end{array}$ & $\begin{array}{c}5.58 \\
0.40 \\
1.34 \\
12.2 \\
2.47 \\
4.39 \\
17.7 \\
17.4 \\
3.21 \\
0.66\end{array}$ & $\begin{array}{l}22.3 \\
2.04 \\
5.53 \\
28.4 \\
4.63 \\
5.74 \\
14.2 \\
10.3 \\
0.68 \\
0.13\end{array}$ & $\begin{array}{l}0 \\
0 \\
0 \\
0 \\
0 \\
0 \\
3.67 \\
0.40 \\
0.19 \\
0.17\end{array}$ & $\begin{array}{c}2.85 \\
0.28 \\
1.80 \\
10.7 \\
3.06 \\
5.00 \\
21.1 \\
23.7 \\
3.06 \\
1.98\end{array}$ \\
\hline $\begin{array}{l}\text { 2-methyl-2-butene } \\
\text { trans-1,3-pentadiene } \\
\text { cyclopentadiene } \\
\text { cis-1,3-pentadiene } \\
\text { neo-hexane } \\
\text { cyclopentene } \\
\text { 4-methyl-1-pentene } \\
\text { 3-methyl-1-pentene } \\
\text { 2, 3-dimethyl-1-butene } \\
\text { cyclopentene }\end{array}$ & $\begin{array}{l}\text { 2MB2 } \\
\text { trans-1,3-PDe } \\
\text { CPDe } \\
\text { cis-1,3-PDe } \\
\text { neo-Ha } \\
\text { CPe } \\
\text { 4MPel } \\
\text { 3MPel } \\
2,3 \mathrm{DBMel} \\
\mathrm{CPa}\end{array}$ & $\begin{array}{l}1.07 \\
5.15 \\
6.56 \\
3.72 \\
0 \\
2.84 \\
0.02 \\
0 \\
0 \\
2.59\end{array}$ & $\begin{array}{l}0.20 \\
4.06 \\
0 \\
1.80 \\
0 \\
0 \\
0 \\
0 \\
0 \\
0\end{array}$ & $\begin{array}{c}0.20 \\
15.1 \\
2.13 \\
7.60 \\
0.62 \\
6.97 \\
0.95 \\
0.46 \\
0.51 \\
3.55\end{array}$ & $\begin{array}{l}2.14 \\
10.6 \\
7.10 \\
3.72 \\
0 \\
2.67 \\
0 \\
0 \\
0 \\
0.29\end{array}$ \\
\hline $\begin{array}{l}\text { 4-methyl-2-pentene } \\
\text { 2, 3-dimethyl butane } \\
\text { 2-methyl pentane } \\
\text { 2-methyl-1-pentene } \\
\text { 3-methyl pentane } \\
\text { trans-2-hexene } \\
\text { n-hexane } \\
\text { 2, 2-dimethyl pentane } \\
\text { dicyclopentadiene }\end{array}$ & $\begin{array}{l}4 \mathrm{MPe} 2 \\
2,3 \mathrm{MBa} \\
2 \mathrm{MPa} \\
2 \mathrm{MPel} \\
3 \mathrm{MPa} \\
\text { trans-2-He } \\
n-\mathrm{Ha} \\
2,2 \mathrm{MPe} \\
\mathrm{DCPDe}\end{array}$ & $\begin{array}{l}0.81 \\
0.17 \\
3.44 \\
0 \\
2.01 \\
0 \\
2.28 \\
0 \\
4.03\end{array}$ & $\begin{array}{l}0 \\
0 \\
0 \\
0 \\
0 \\
0 \\
0 \\
0 \\
0\end{array}$ & $\begin{array}{l}3.24 \\
0.63 \\
10.1 \\
1.11 \\
6.39 \\
0.30 \\
7.80 \\
1.29 \\
26.7\end{array}$ & $\begin{array}{l}0 \\
0 \\
0 \\
0 \\
0 \\
0 \\
0 \\
0 \\
0\end{array}$ \\
\hline
\end{tabular}




\subsection{Materials}

Isoprene used for this study was of polymerization grade $\left(99.8 \mathrm{~mol}^{\circ}, \mathrm{o}\right)$ and 2-methyl-2-butene of $97.5 \mathrm{~mol} \%$ purity containing other isomeric $C_{i}$ olefines as impurities.

$\mathrm{C}_{5}$ fraction was obtained from an ethylene plant and had a composition shown in Table 1. It was fed onto the 21 st plate of the Oldershow tower and distilled under the reflux ratio of 15 . Low boiling components consisted mainly of $\mathrm{C}_{4}$ and high boiling components mainly consisted of $\mathrm{C}_{6}$ and dicyclopentadiene, which formed by the dimerization of cyclopentadiene during the storage, were withdrawn from the top and the bottom, respectively. The side cut fraction containing about $20 \%$ isoprene and $25 \%$ n-pentane was collected as the feed stock for the extractive distillation runs. The typical composition of the feed stock is shown in Table 1 together with that of the top and the bottom streams. The temperature on the side cut plate, the top and the bottom were 34,26 and $87^{\circ} \mathrm{C}$, respectively.

The solvents used were all commercially available reagents of extra pure grade and were used without any further purification. To prevent from the polymerization of dienes during extractive distillation, $0.2 \mathrm{wt} \%$ of $t$-butyl-pyrrocatechol ${ }^{3 \text { ) }}$ was added to the solvent.

\section{Result and Discussion}

\subsection{Effects of Operating Conditions on the Separation}

Various factors which influence on the separation were considered to be top reflux ratio $(R)$, solvent temperature $\left(T_{S}\right)$, feed temperature $\left(T_{f}\right)$, the position of feed plate $\left(\mathbf{P}_{\mathrm{f}}\right)$, boilup rate, solvent flow rate and kinds of solvents. Among these factors, the boilup rate wass kept approximately constant by maintaining a constant heat input and the solvent flow rate at $50 \mathrm{cc} / \mathrm{min}$. which was limited by the flexibility of the tower.

The hydrocarbon feed used in all runs was equimolal mixture of isoprene with 2-methyl-2-butene. The degree of separation (S) between both components was cxpressed as

$$
S=\frac{x_{0} /\left(1-x_{e}\right)}{x_{t} /\left(1-x_{t}\right)}
$$

where, $x_{e}$ and $x_{t}$ represent the molal concentrations of isoprene in the distillates from the top of stripper and extractive distillation tower, respectively. The recovery (Rv) means the percentage of isoprene recovered in the extract divided

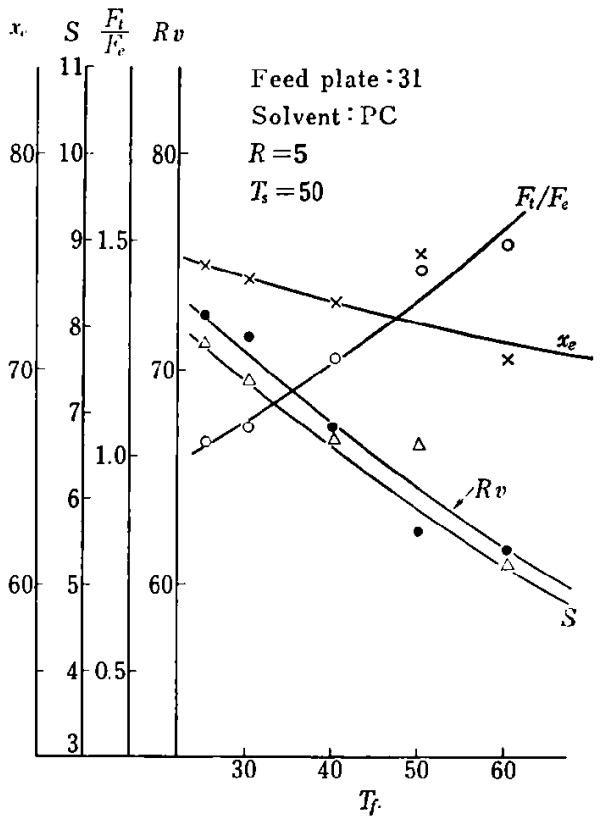

Fig. 2 Effect of hydrocarbon Feed Temperature $T_{f}$

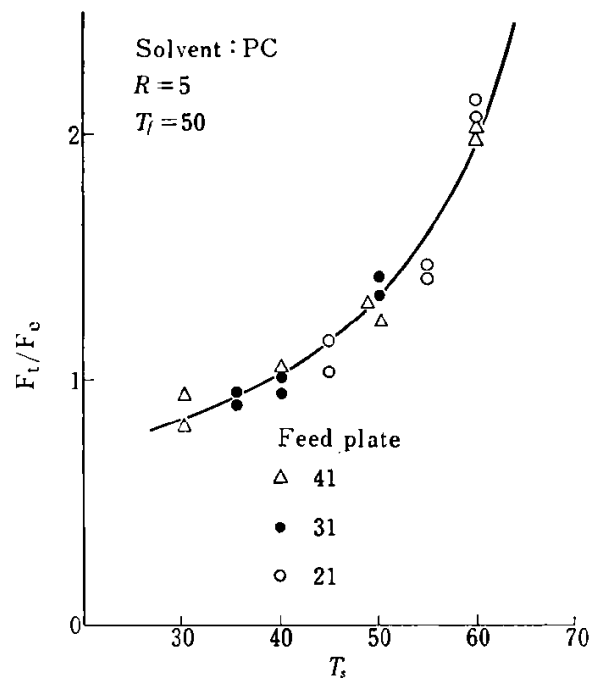

Fig. 3 Effect of Solvent Temperature on $F_{t} / F_{\theta}$

by the total isoprene in the hydrocarbon feed. $F_{t}$ and $F_{e}$ are the distillate rates of raffinate and extract, respectively.

Table 2 shows the experimental results obtained in the extractive distillation runs using $P C$ as a solvent. The hydrocarbon feed plate was varied on the $21 \mathrm{st}$, the 31 st and the 41 st plate counted from the top. The tower liquid sampling apparatus was set on the 31 st plate in case the hydrocarbon feed was introduced either onto the 21 st or the 41 st plate, and onto the 21 st plate in case it was introduced onto the 31 st plate.

Fig. 2 shows the effects of the hydrocarbon feed temperature on the extract purity $\left(x_{e}\right), F_{t} / F_{e}$, 
Table 2 Experimental Data Obtained in the Extractive Distillation of

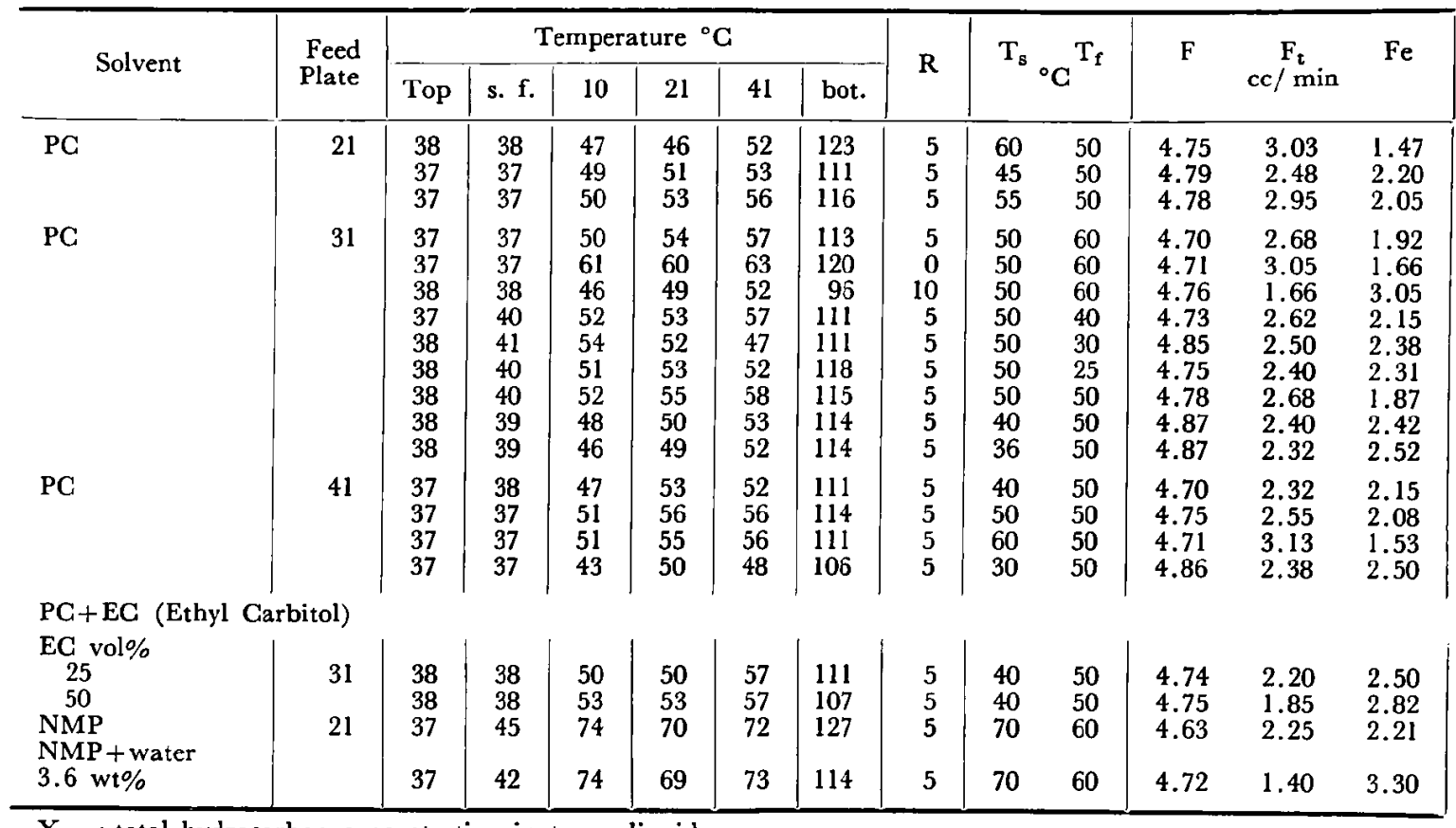

$\mathrm{X}_{\mathrm{HC}}$ : total hydrocarbon concentration in tower liquid

$x_{t}$ : isoprene content in the distillate from top of extractive distillation tower

$x_{e}$ : isoprene content in the distillate from top of stripper

degree of separation (S) and the recovery of isoprene in the extract. It is obvious that low temperature gives good result from the standpoint of the separation and the recovery, though these values varied relatively little compared with the influence of solvent temperature which will be mentioned later.

Fig. 3, 4 and Fig. 5 show the influences of solvent temperatures on the solvent feed inlet and locations of the hydrocarbon feed plate. From these figures it is clear that the location of the hydrocarbon feed plate did not effect on the $F_{t} / F_{e}$, the degree of separation and the recovery. While, the solvent temperature gave such large effects by increasing $\mathrm{T}_{\mathrm{s}}$ from 40 to $60^{\circ} \mathrm{C}$, that the value of $F_{t} / F_{\theta}$ almost doubled (Fig. 3), the respective $S$ value decreased to the half (Fig. 4) and the recovery of isoprene also decreased from $75 \%$ to $50 \%$. From Fig. 4 and Fig. 5, the lower the solvent temperature was, the more effective separation seemed possible in case of the extractive distillation of isoprene and 2methyl-2-butene using $\mathrm{PC}$ as a solvent.

The effects of the reflux ratios at the top of the extractive distillation tower are shown in Fig. 6, which suggested that, by taking high reflux ratio, the recovery of isoprene increased but the purity in the extract was not necessarily improved because the value of $F_{t} / F_{e}$ decreased linearly. From these

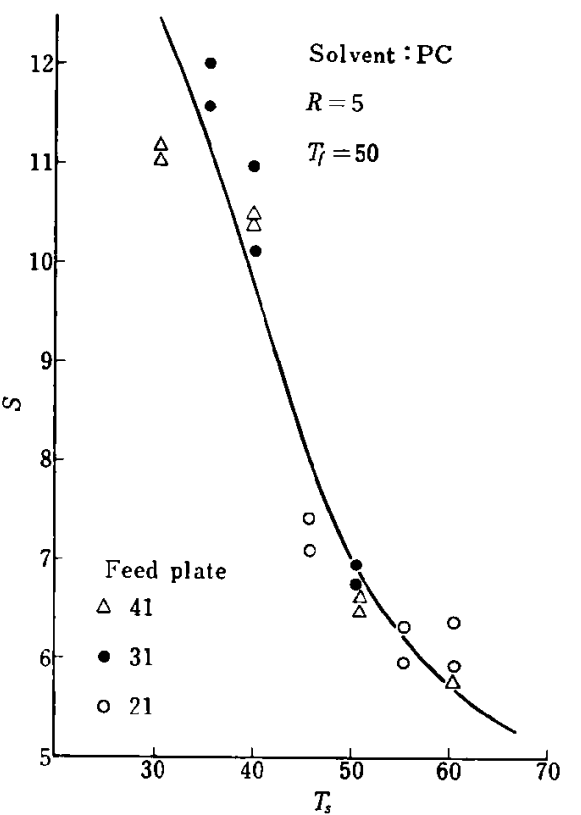

Fig. 4 Effect of Solvent Temperature on the separability (S) between Isoprene and 2-Methyl-2butene

result it may be concluded that the temperature of the solvent is the most effective factor and low temperature is desirable in the extractive distillation of binary mixture of isoprene and 2methyl-2-butene. One reason for this result may be that the temperature gradient becomes large throughout the tower and another may be that 
Isoprene-2 Methyl-2-Butene Mixture

\begin{tabular}{|c|c|c|c|c|c|}
\hline$F_{t} / F_{e}$ & $\mathrm{x}_{\mathrm{t}} \mathrm{mol}$ & $\%{ }^{x_{0}}$ & $\mathbf{S}$ & $\begin{array}{l}\mathrm{R}_{\mathrm{v}} \\
\%\end{array}$ & $\begin{array}{c}\mathrm{X}_{\mathrm{HC}} \\
\mathrm{wt} \%\end{array}$ \\
\hline $\begin{array}{l}2.06 \\
1.13 \\
1.44\end{array}$ & $\begin{array}{l}32.6 \\
27.2 \\
32.7\end{array}$ & $\begin{array}{l}75.7 \\
73.3 \\
74.2\end{array}$ & $\begin{array}{l}6.45 \\
7.36 \\
5.93\end{array}$ & $\begin{array}{l}52.7 \\
70.3 \\
61.1\end{array}$ & $\begin{array}{l}- \\
9.3 \\
8.9\end{array}$ \\
\hline $\begin{array}{l}1.48 \\
1.84 \\
0.54 \\
1.22 \\
1.05 \\
1.03 \\
1.43 \\
0.99 \\
0.92\end{array}$ & $\begin{array}{l}30.9 \\
39.3 \\
20.9 \\
29.0 \\
28.0 \\
27.5 \\
32.5 \\
23.5 \\
22.4\end{array}$ & $\begin{array}{l}70.1 \\
68.0 \\
65.6 \\
73.0 \\
74.2 \\
74.5 \\
76.5 \\
77.6 \\
77.8\end{array}$ & $\begin{array}{c}5.25 \\
3.27 \\
7.21 \\
6.63 \\
7.39 \\
7.87 \\
6.76 \\
11.3 \\
12.1\end{array}$ & $\begin{array}{l}61.8 \\
48.2 \\
85.0 \\
67.1 \\
71.4 \\
72.4 \\
62.0 \\
76.7 \\
78.8\end{array}$ & $\begin{array}{l}7.7 \\
6.4 \\
9.6 \\
8.2 \\
7.7 \\
7.7 \\
7.7 \\
9.0 \\
9.6\end{array}$ \\
\hline $\begin{array}{l}1.08 \\
1.22 \\
2.04 \\
0.95\end{array}$ & $\begin{array}{l}24.8 \\
30.6 \\
36.1 \\
22.1\end{array}$ & $\begin{array}{l}77.6 \\
74.8 \\
76.7 \\
76.7\end{array}$ & $\begin{array}{c}10.5 \\
6.71 \\
5.85 \\
11.2\end{array}$ & $\begin{array}{l}74.1 \\
66.3 \\
50.8 \\
77.6\end{array}$ & $\begin{array}{r}10.3 \\
8.4 \\
8.1 \\
10.8\end{array}$ \\
\hline $\begin{array}{l}0.88 \\
0.66 \\
1.02\end{array}$ & $\begin{array}{l}21.5 \\
20.3 \\
31.9\end{array}$ & $\begin{array}{l}67.4 \\
63.8 \\
60.8\end{array}$ & $\begin{array}{l}7.55 \\
6.91 \\
3.31\end{array}$ & $\begin{array}{l}77.9 \\
82.5 \\
65.0\end{array}$ & $\begin{array}{r}8.8 \\
11.2 \\
17.1\end{array}$ \\
\hline 0.44 & 15.1 & 71.1 & 13.9 & 91.4 & 7.8 \\
\hline
\end{tabular}

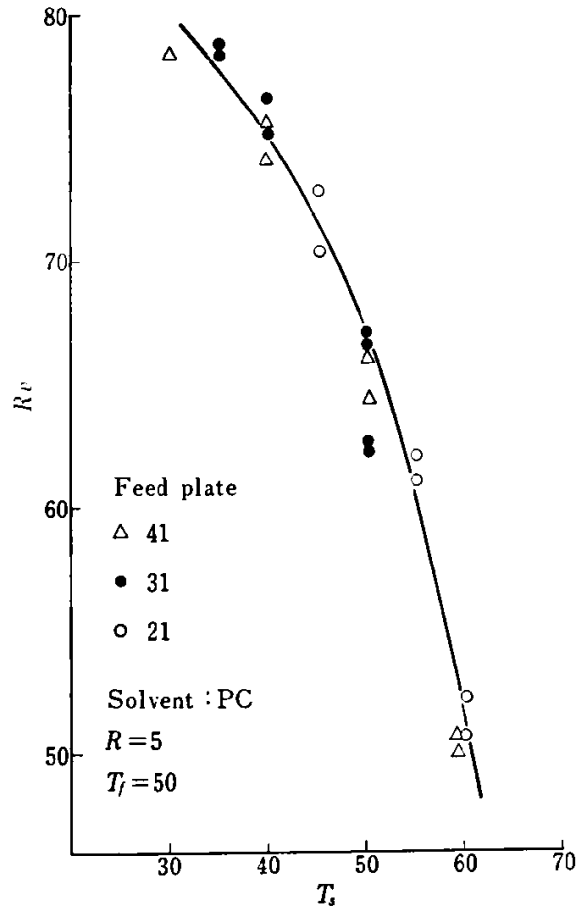

Fig. 5 Effect of Solvent Temperature on Isoprene Recovery $\mathrm{Rv}$

the internal reflux which occurs and promotes the vapor-liquid contact in the tower by lowering the solvent temperature.

The effect of solvent composition containing ethyl carbitol (EC) which was added to improve the solubility for hydrocarbons was tested.

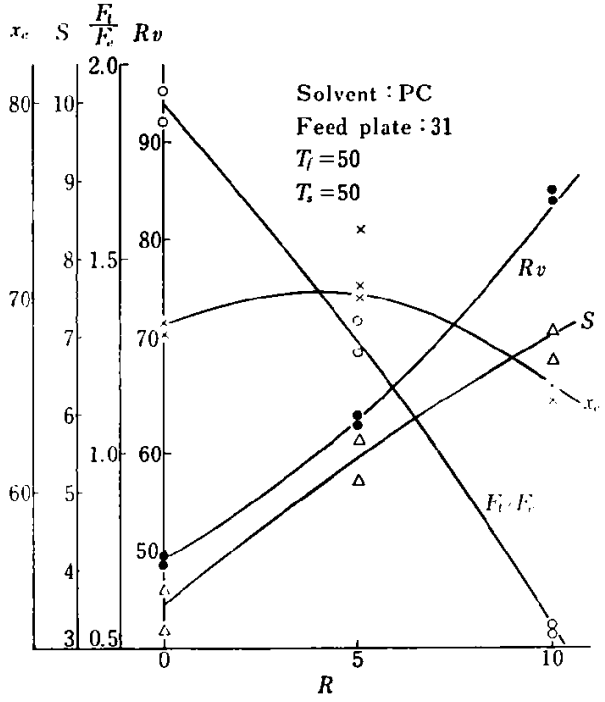

Fig. 6 Effect of Reflux Ratio

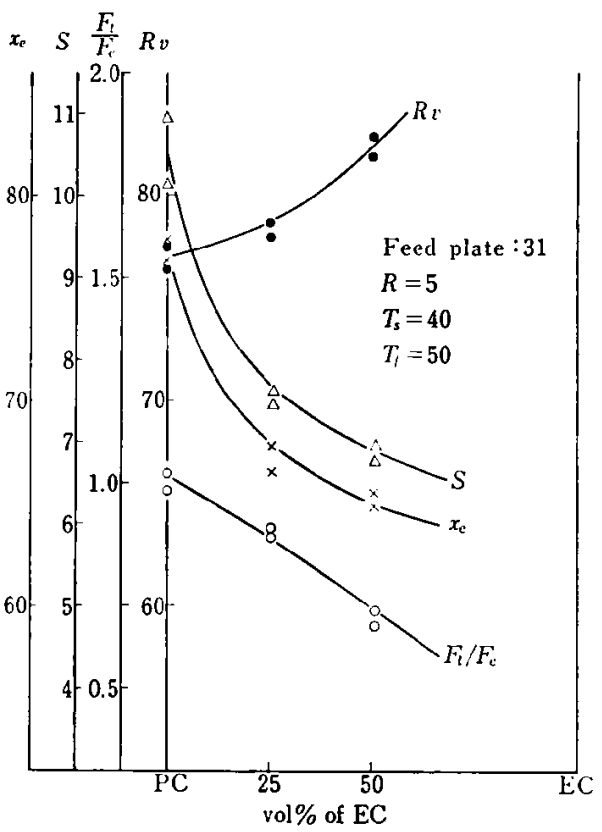

Fig. 7 Effect of Solvent Composition for PC-EC Binary Solvent

Fig. 7 suggests that by adding EG into $P C$ the recovery of isoprene could be improved, while the separation tended to decrease.

The results are also given in Table 2 which were obtained using NMP and NMP containing $3.6 \mathrm{wt} \%$ of water. A solvent such as NMP which is highly miscible with hydrocarbons tends to make the hydrocarbon concentration in the tower liquid high and relatively high solvent temperature was needed to keep the same hydrocarbon concentration as that in case of PC. While, by adding water into NMP the hydrocarbon concentration could be suppressed to give the high 
degree of separation $(S=13.9)$ and high recovery. In case the solvent contained water, it was considerably difficult to carry out the experiment because the water was removed with the distillates to vary gradually the solvent composition. Another merit of adding water was that the stripping temperature could be lowered and the hydrocarbon components were almost completely purged from the rich solvent.

Though low temperature was desirable as mentioned before, it seemed impractical to cool the solvent until such temperature as an additional cooling system was needed, taking account of heat economy in the practical plant operation. The solvent temperature practically applicable may range from 40 to $50^{\circ} \mathrm{C}$ taking account of the heat exchange with the feed. For this reason we carried out the runs on the extractive distillation of $\mathrm{C}_{5}$ fraction at the solvent temperature of $50^{\circ} \mathrm{C}$.

\section{2 $\mathrm{G}_{5}$ Fraction as a Feed}

Table 3 shows the composition of feed, the raffinate, the extract and the samples from the upper and the lower sampling outlet. The operating conditions are also shown. The extract mainly consisted of dienes, especially it contained over $50 \%$ isoprene. The content of cyclopenta- diene in the feed was considerably less than that of the side cut shown in Table 1 because it tended to polymerize during the storage. N-Fentane was not detected in the extract. This is specially significant because it forms an azeotropic mixture with isoprene and this makes it difficult to obtain pure isoprene by superfractionation of the extract. The results of recoveries of various components in the extract are given in Table 3 , in which the recovery of isoprene was $63 \%$. From the analytical data of samples taken at several points, a peak in the isoprene concentration seemed to exist near the 40th plate, after which other diene components such as trans- and cis-1,3- pentadiene, cyclopentadiene and cyclopentene became richer to the extract.

As mentioned in the result of the extractive distillation of binary hydrocarbon mixture, this relatively low recovery was probably due to the low solubility between $\mathrm{PC}$ and $\mathrm{C}_{5}$ hydrocarbons. To obtain high recoveries of dienes in the extract, we tried to improve the miscibility of PC by adding another solvent which has high solubility for hydrocarbons and relatively high selectivity to dienes such as diethylene glycol monoethylether (ethyl carbitol). Fig. 8 shows the solubility of isoprene, 2-methyl-2-butene and n-pentane into the mixed

Table 3 Operating Conditions, Compositions of Samples and Recovery in Extract Using Propylene Carbonate

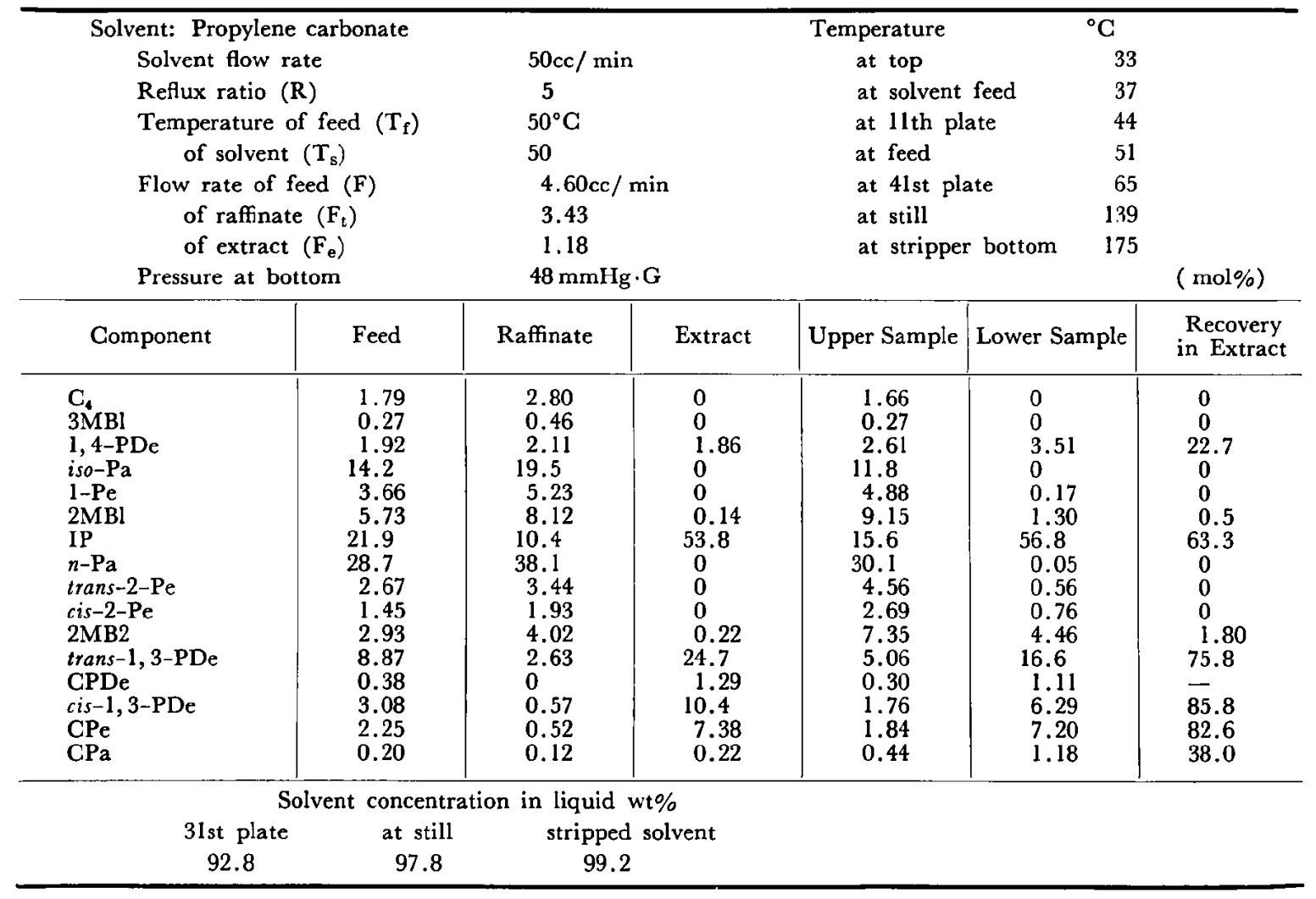


Table 4 Operating Conditions, Compositions of Samples and Recovery in Extract Using a Mixed Solvent

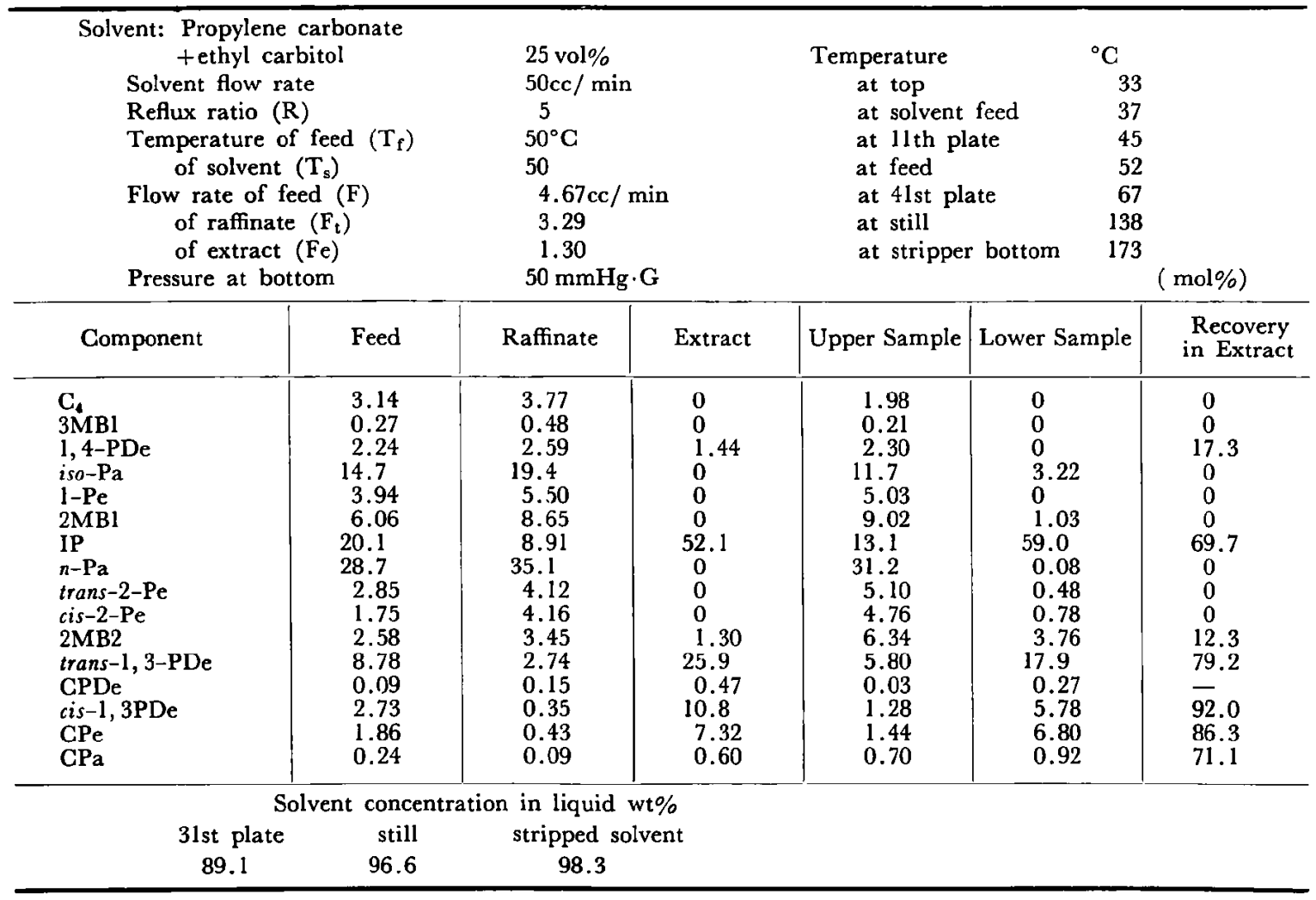

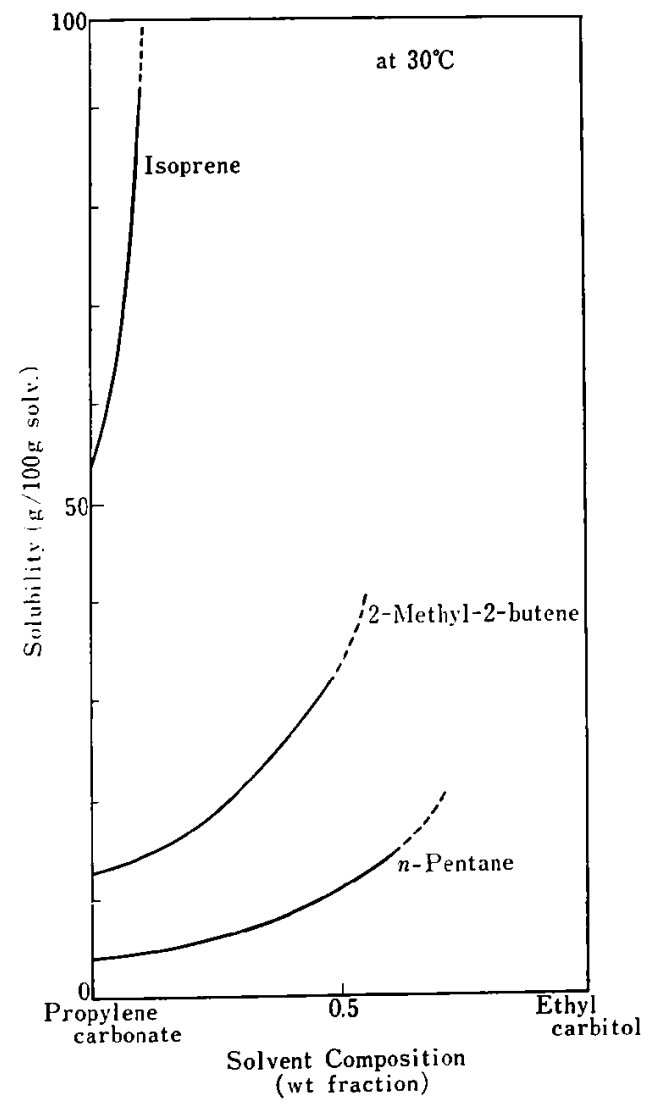

Fig. 8 Solubility of Isoprene, 2-Methyl-2-Butene and $n$-Pentane in a Mixed Solvent Consisting of ProPylene carbonate and Ethyl-Carbitol solvent consisting of $\mathrm{PC}$ and EC. By adding EC, the solubility of isoprene increased rapidly, while those of 2-methyl-2-butene and $n$-pentane gradually increased. From these results, the mixed solvent was considered to be of high selectivity and to give proper solubility with a hydrocarbon feed by adjusting the solvent composition.

Table 4 shows the compositions of the extract and the raffinate in the extractive distillation using the mixed solvent consisting of $\mathrm{PC}$ ( $75 \mathrm{vol} \%$ ) and EC $(25 \mathrm{vol} \%)$. The recoveries of dienes in the extract, compared with the result in Table $\mathbf{3}$, were improved without remarkable decrease in the diene purity.

The solvent used for a certain length of time had to be purified to eliminate the polymers accumulated during the recycling. Since these solvents boil at above $200^{\circ} \mathrm{C}$, the distillation was made under the reduced pressure of about $100 \sim$ $200 \mathrm{mmHg}$ abs. to avoid thermal cracking of the solvent.

\section{Conclusion}

Using a binary mixture of isoprene and 2methyl-2-butene as a feed charge, the effects of various operating parameters on the separation in the extractive distillation were investigated. As 
a result the separation was largely dependent on the solvent temperature and low temperatures were found more effective in this study.

Propylene carbonate was tested as an extractive distillation solvent to separate the dienes from a $\mathrm{G}_{5}$ fraction. A fraction containing no paraffins and only a trace of olefins was obtained from the top of the stripper which had a possible composition to give highly purc isoprene by super-fractionation.
Propylene carbonate exhibited high selectivity for dienes but relatively poor miscibility with $\mathrm{C}_{5}$ hydrocarbons. By adding ethyl carbitol to increase the miscibility, the diene recovery could be improved.

\section{References}

1) Enomoto, M, Bull. Japan. Petrol. Inst., 13, 169 (1971).

2) Enomoto, M, Bull. Nat. Res. Inst. Pol. Res., 2, 19 (1972).

3) Enomoto, M, ibid., 5, 21 (1976). 